Supporting Information

\title{
Measuring the Energy Barrier of the Structural Change that Initiates
} Amyloid Formation

Blaise G. Arden, Nicholas B. Borotto, Brittney Burant, William Warren, Christine Akiki, and Richard W. Vachet*

Department of Chemistry, University of Massachusetts Amherst, Amherst, Massachusetts 01003, United States.

* Corresponding author email address: rwvachet@chem.umass.edu 


\section{Table of Contents}

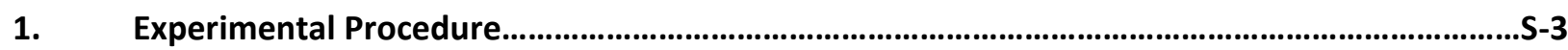

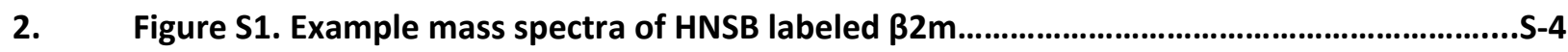

3. Figure S2. Extent of HNSB labeling on Trp60 vs Trp95 ...............................................................

4. Figure S3. Extent of HNSB labeling when incubated with $\mathrm{Cu}(\mathrm{II})$ and urea..................................5-5

5. Figure S4. Comparing HNSB labeling to ThT fluorescence......................................................

6. Figure S5. Extent of HNSB labeling in the presence of TFE........................................................

7. Figure S6. Extent of HNSB labeling on Trp60 vs Trp95 under acidic conditions..........................S-7

8. Figure S7. Comparison of HNSB labeling, ThT fluorescence, and DLS under acidic conditions.S-8

9. Figure S8. Comparison of Trp60 burial rate at different temperatures......................................8-8

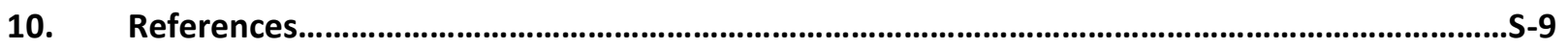




\section{Experimental Procedure:}

Materials. Dimethyl (2-hydroxy-5-nitrobenzyl) sulfonium bromide (HNSB), 3morpholinopropanesulfonic acid (MOPS), potassium acetate, zinc sulfate, trifluoroethanol (TFE), Thioflavin T (ThT), triethylamine (TEA), iodoacetamide, tris(2-carboxyethyl)phosphine hydrochloride (TCEP), and L-tryptophan were obtained from Sigma-Aldrich (St. Louis, MO). Human $32 \mathrm{~m}$ purified from human urine was purchased from Lee Biosolutions (Maryland Heights, MO). Acetonitrile (ACN), potassium phosphate, glacial acetic acid, citric acid, sodium citrate, copper sulfate, and nickel sulfate were obtained from Fisher Scientific (Fair Lawn, NJ). Immobilized chymotrypsin was obtained from Princeton Separations (Adelphia, NJ). Urea was obtained from MP Biomedicals, LLC (Solon, OH). Deionized water was prepared from a Millipore (Burlington, MA) Simplicity 185 water purification system.

Covalent Labeling Sample Preparation. For all metal and TFE experiments, a $75 \mu \mathrm{M}$ stock of $\beta 2 \mathrm{~m}$ was made in $25 \mathrm{mM}$ MOPS and $150 \mathrm{mM}$ potassium acetate at $\mathrm{pH}$ 7.4. For all acid experiments, a $150 \mu \mathrm{M}$ stock of $\beta 2 \mathrm{~m}$ was made in HPLC water. For all experiments, molar ratios of metal to $\beta 2 \mathrm{~m}$ were chosen such that $95 \%$ of proteins in solution were bound (based on previously reported measurements) and

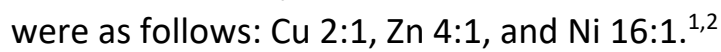

Thioflavin T Fluorescence. Fluorescence experiments where performed on a PTI QuantaMaster 4 SE spectrofluorometer. Measurements were taken at excitation and emission wavelengths of $437 \mathrm{~nm}$ and $483 \mathrm{~nm}$, respectively. $\mathrm{Cu}(\mathrm{II})$ initiated samples contained $25 \mathrm{mM}$ MOPS (at pH 7.4), $150 \mathrm{mM}$ potassium acetate, $500 \mathrm{mM}$ urea, $50 \mu \mathrm{M} \beta 2 \mathrm{~m}, 80 \mu \mathrm{M}$ ThT and were equilibrated at $37^{\circ} \mathrm{C}$ for 15 minutes before adding $\mathrm{Cu}(\mathrm{II})$. After the addition of $100 \mu \mathrm{M} \mathrm{Cu}(\mathrm{II})$, the sample was immediately analyzed. Acid initiated samples contained $108 \mu \mathrm{M} \beta 2 \mathrm{~m}$ and $160 \mu \mathrm{M}$ ThT. Analysis was started immediately after introduction of $\beta 2 m$ into the acidic buffer.

Dynamic Light Scattering. DLS was performed on a Malvern Zetasizer Nano ZSP set in size analysis mode. Data collection was performed at $22{ }^{\circ} \mathrm{C}$. Samples contained $30 \mu \mathrm{M} \beta 2 \mathrm{~m}$ in $150 \mathrm{mM}$ citrate buffer at pH 3.5 and were analyzed immediately after introduction of $\beta 2 \mathrm{~m}$ into the acidic condition.

Proteolytic Digestion and LC/MS/MS. HNSB labeled $\beta 2 \mathrm{~m}$ samples were digested using chymotrypsin. First, labeled $\beta 2 \mathrm{~m}$ samples were unfolded by $50 \mathrm{mM}$ TEA with $10 \% \mathrm{ACN}$ at $50^{\circ} \mathrm{C}$ for $45 \mathrm{~min}$. Next, disulfide bonds were reduced by reaction with TCEP at $37^{\circ} \mathrm{C}$ for $15 \mathrm{~min}$ and cysteine's alkylated by reaction with iodoacetamide at room temperature for $30 \mathrm{~min}$. Immobilized chymotrypsin was then added to yield an enzyme/protein ratio of $1: 10$ and incubated at $37^{\circ} \mathrm{C}$ for 3 hours. Digested samples were then centrifuged to separate the digestion enzyme and analyzed by LC/MS/MS. LC separation of the digests were performed on a $\mathrm{C} 18$ reverse phase column using water and $\mathrm{ACN}$ as mobile phases with a gradient from $1 \% \mathrm{ACN}$ to $99 \% \mathrm{ACN}$ over $80 \mathrm{~min}$.

Data Fitting. HNSB labeling curves were fit with the exponential equation: $Y=Y_{0}+A e^{k_{0} x}$. Where $Y_{0}$ is the asymptotic limit, $\mathrm{k}$ is the rate, $\mathrm{A}$ is a pre-exponential factor, and $\mathrm{x}$ is time.

Activation Energy Calculations. The Arrhenius equation of the form $\ln k_{r}=\ln A-\frac{E_{a}}{R T}$ was used to determine the activation energy $\left(E_{a}\right)$ from the rates of Trp60 burial at different temperatures. $k_{r}$ is the Trp60 burial rate, $A$ is the Arrhenius preexponential factor, $R$ is the gas constant, and $T$ is the temperature. The Eyring equation of the form $\mathrm{k}_{r}=\mathrm{\kappa e}^{2} \mathrm{~B} \mathrm{e}^{\frac{\Delta \mathrm{S}}{\mathrm{R}}} \mathrm{e}^{-\frac{\mathrm{E} a}{\mathrm{RT}}}$ was used to relate activation energy 
$\left(\mathrm{E}_{\mathrm{a}}\right)$ to activation entropy $(\Delta \mathrm{S})$ where $\mathrm{B}=\frac{k T}{h} \frac{R T}{p^{\circ}}$. $\kappa$ and $p^{\circ}$ are each taken to be 1 , as is the most common form, and $h$ is Planck's constant.
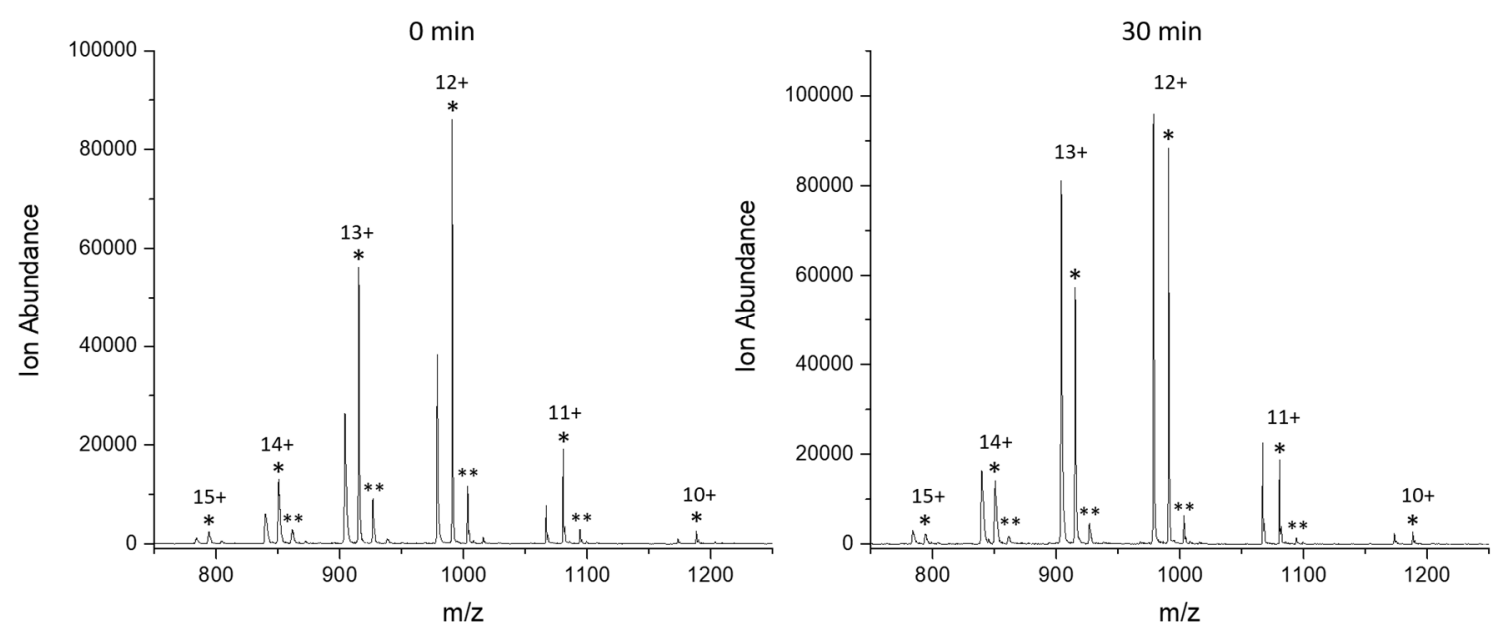

Figure S1. Example electrospray ionization mass spectra of $\beta 2 \mathrm{~m}$, showing a decreased extent of covalent labeling with HNSB 30 min after adding $\mathrm{Cu}(\mathrm{II})$. The asterisk $\left(^{*}\right)$ indicates the HNSB-labeled $\beta 2 \mathrm{~m}$ peaks in the mass spectra.

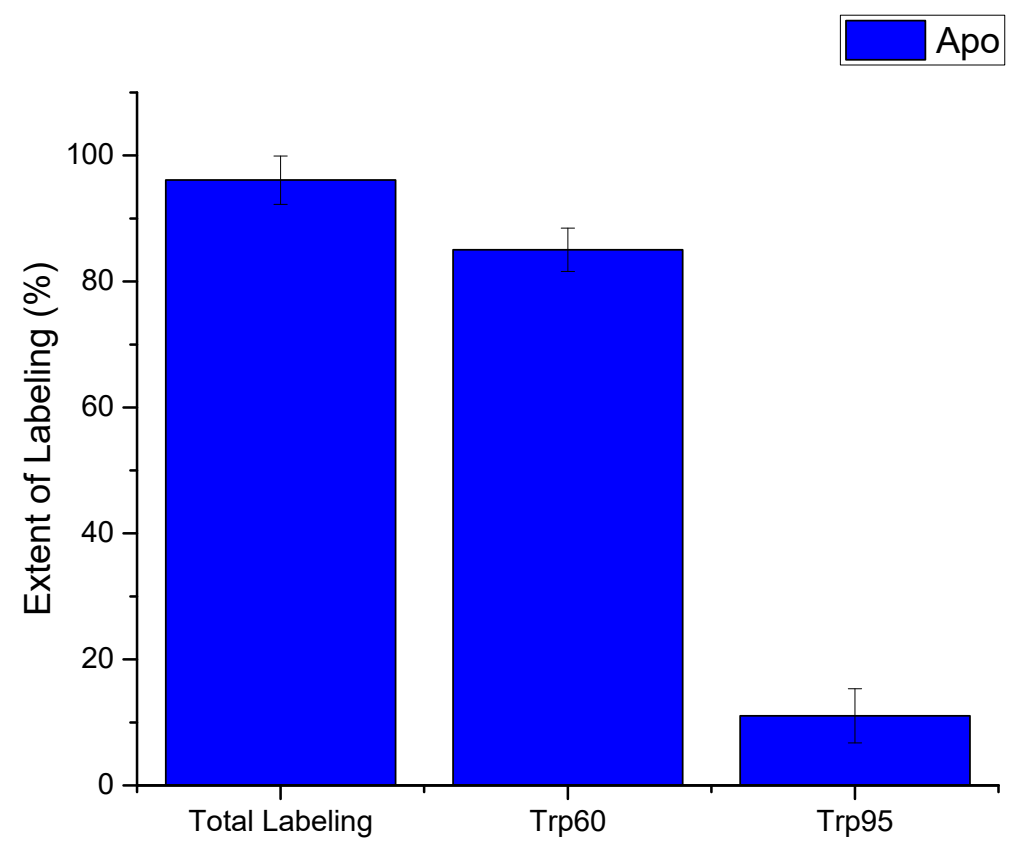

Figure S2. Extent of HNSB labeling from proteolytic digestion followed by LC-MS/MS of $\beta 2 \mathrm{~m}$, indicating total labeling and labeling at Trp60 from measured peptide Asp59-Tyr63 and labeling at Trp95 from measured peptides Trp95-97 and Trp95-Met99. 


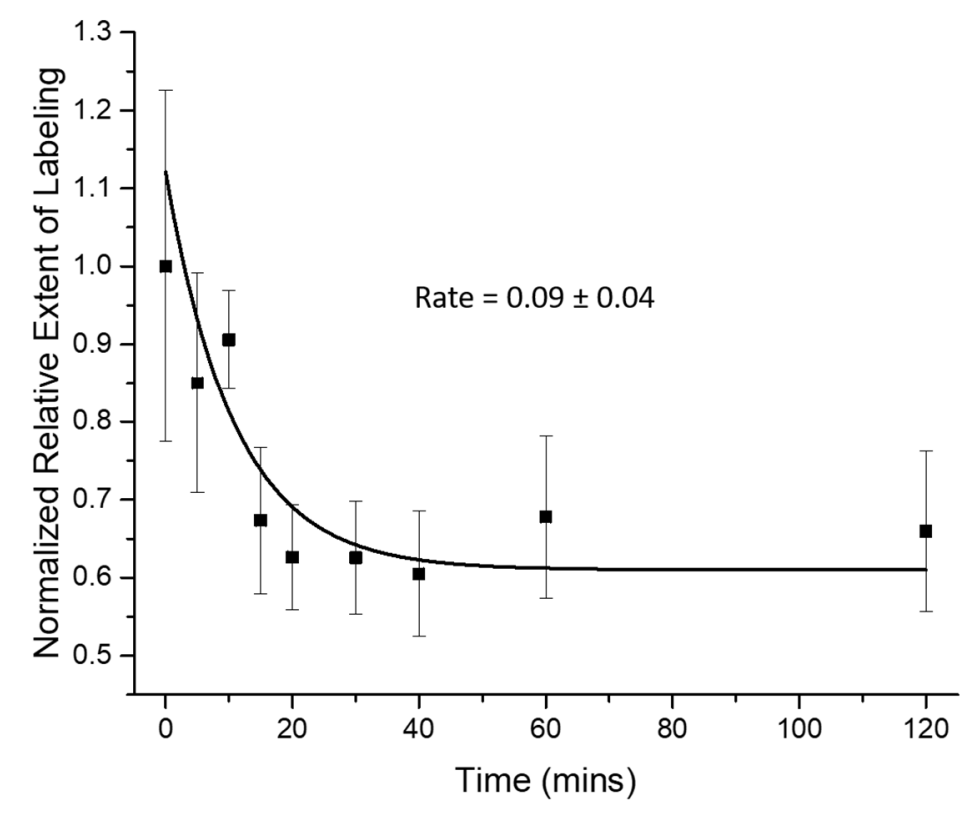

Figure S3. Extent of HNSB labeling on $\beta 2 \mathrm{~m}$ when incubated with $\mathrm{Cu}(\mathrm{II})$ and $500 \mathrm{mM}$ urea over a $120 \mathrm{~min}$ period.

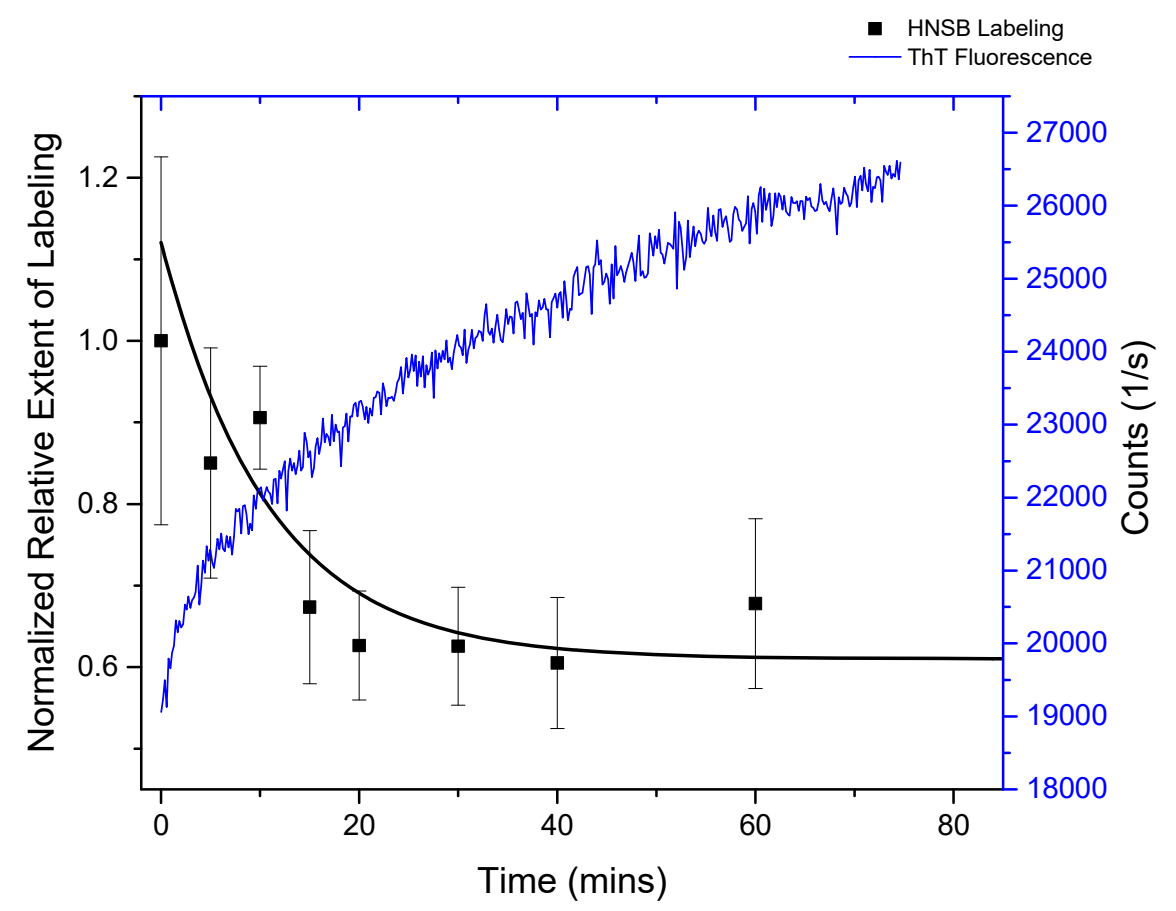

Figure S4. Comparison of HNSB Trp labeling data with ThT fluorescence data at $22^{\circ} \mathrm{C}$ when incubated with $\mathrm{Cu}(\mathrm{II})$ and $500 \mathrm{mM}$ urea. 


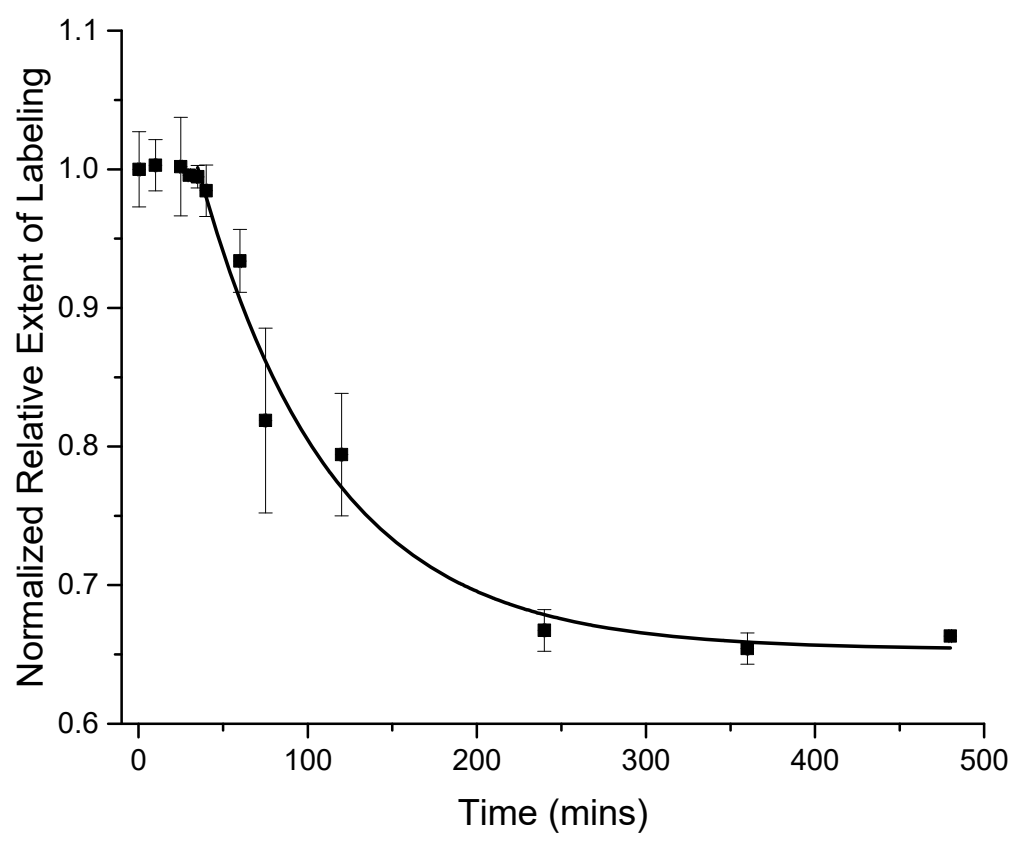

Figure S5. Trp burial in $\beta 2 \mathrm{~m}$ using HNSB in the presence of $20 \%$ TFE at $22{ }^{\circ} \mathrm{C}$. Data were fit after the 40 min lag period, giving a rate of $0.013 \pm 0.003 \mathrm{~min}^{-1}$. Experiments were conducted with $75 \mu \mathrm{M} \beta 2 \mathrm{~m}$ in 25 $\mathrm{mM}$ MOPS and $150 \mathrm{mM}$ potassium acetate at $\mathrm{pH}$ 7.4. 


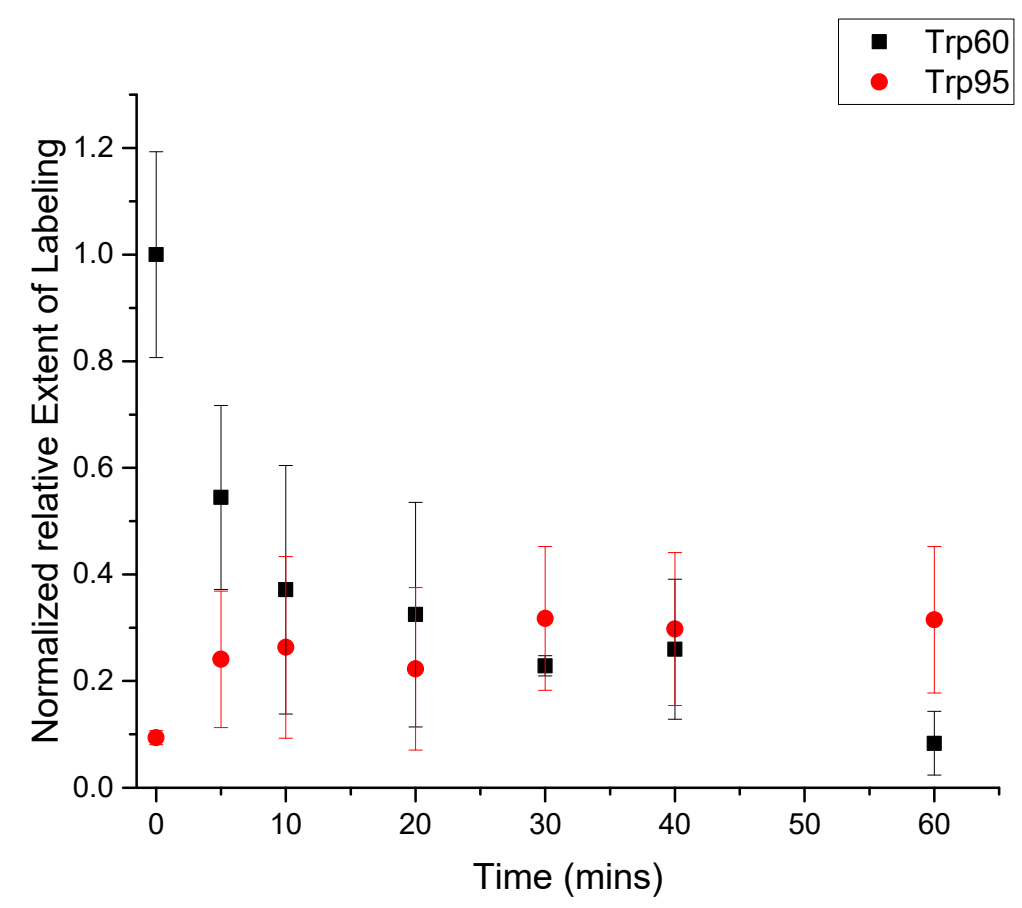

Figure S6. Extent of HNSB labeling on Trp60 and Trp95 over time after initiation with acid at pH 3.5. These data were obtained from proteolytic digestion followed by LC-MS/MS analysis of $\beta 2 \mathrm{~m}$. Trp labeling at Trp60 is an average of the values from the following measured peptides Ser55-Trp60, Ser57Trp60, Ser57-Phe62, and Ser57-Tyr63, and labeling at Trp95 is an average of the values from the following measured peptides Ser88-Trp95, Val93-Met99, and Lys94-Met99. The error bars represent one standard deviation. 


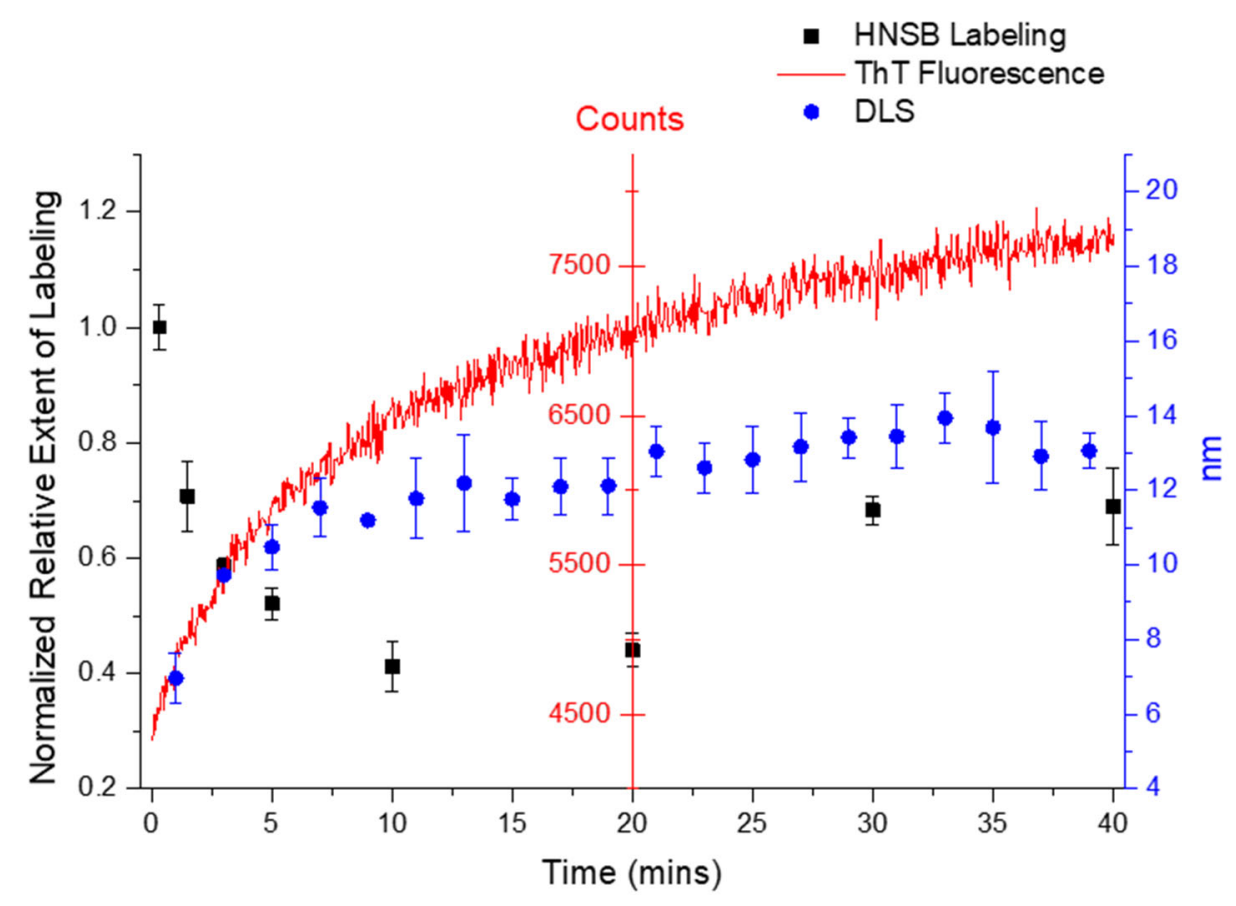

Figure S7. Comparison of CL-MS data with ThT fluorescence and DLS data during the pre-amyloid structural change. All experiments were conducted with $75 \mu \mathrm{M} \beta 2 \mathrm{~m}$ at $\mathrm{pH} 3.5$.

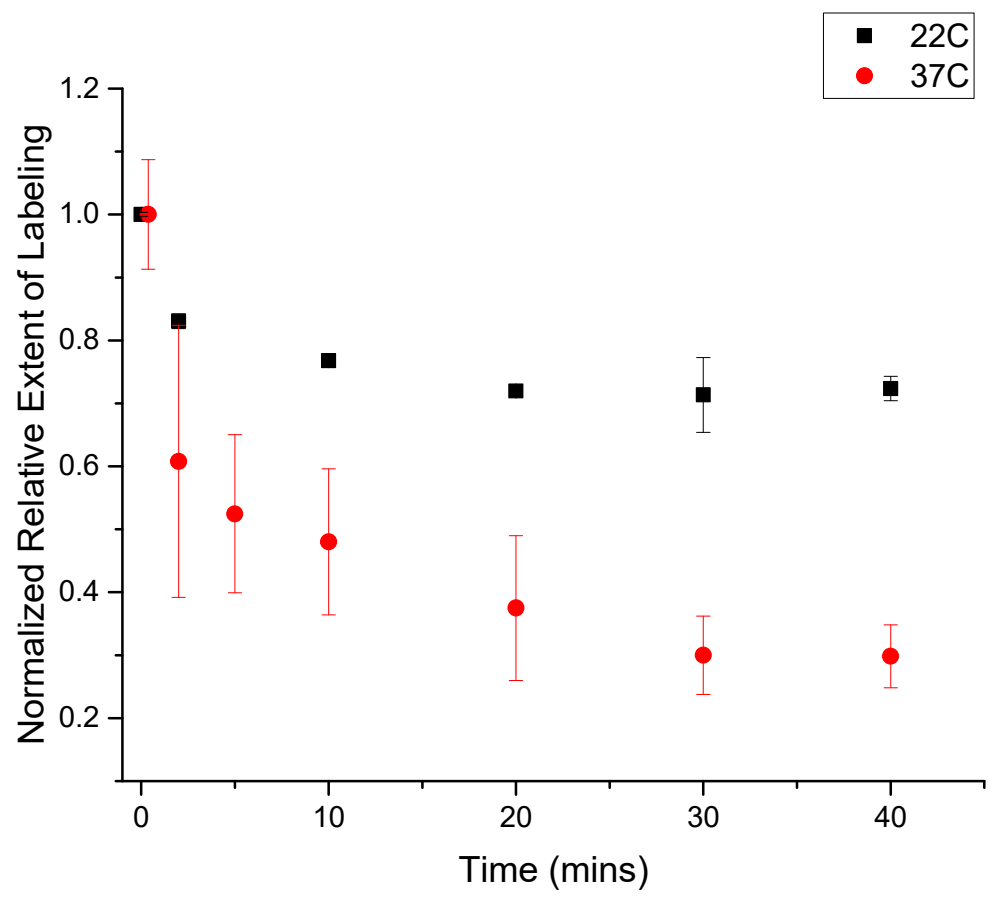

Figure S8. Comparison of the rate of $\operatorname{Trp}$ burial at $22^{\circ} \mathrm{C}$ and $37^{\circ} \mathrm{C}$ for $\mathrm{Cu}(\mathrm{II})$ initiated amyloid reaction. The normalized relative extent of labeling reaches a lower value at $37^{\circ} \mathrm{C}$ primarily because the labeling reaction with HNSB is more extensive at this higher temperature. 


\section{References}

(1) Eakin, C. M.; Knight, J. D.; Morgan, C. J.; Gelfand, M. A.; Miranker, A. D. Formation of a copper specific binding site in non-native states of $\beta$-2-microglobulin. Biochemistry 2002, 41, 1064610656.

(2) Dong, J.; Joseph, C. A.; Borotto, N. B.; Gill, V. L.; Maroney, M. J.; Vachet, R. W. Unique Effect of $\mathrm{Cu}(\mathrm{II})$ in the Metal-Induced Amyloid Formation of $\beta$-2-Microglobulin. Biochemistry 2014, 53, 1263-1274. 